Igor Sukhotnik · Jorge Mogilner - Raanan Shamir Naim Shehadeh · Jacob Bejar · Mark Hirsh

Arnold G. Coran

\title{
Effect of subcutaneous insulin on intestinal adaptation in a rat model of short bowel syndrome
}

Accepted: 15 October 2004/Published online: 25 November 2004

(C) Springer-Verlag 2004

\begin{abstract}
Insulin has been shown to influence intestinal structure and absorptive function. The purpose of the present study was to evaluate the effects of parenteral insulin on structural intestinal adaptation, cell proliferation, and apoptosis in a rat model of short bowel syndrome (SBS). Male Sprague-Dawley rats were divided into three experimental groups: sham rats underwent bowel transection and reanastomosis, SBS rats underwent a 75\% small bowel resection, and SBSINS rats underwent a $75 \%$ small bowel resection and were treated with insulin given subcutaneously at a dose of $1 \mathrm{U} / \mathrm{kg}$, twice daily, from day 3 through day 14 . Parameters of intestinal adaptation, enterocyte proliferation, and enterocyte apoptosis were determined on day 15 following operation. SBS rats demonstrated a significant increase in jejunal and ileal bowel and mucosal weight, villus height and crypt depth, and cell proliferation index compared with the sham group. SBSINS animals demonstrated higher jejunal and ileal bowel and mucosal weights, jejunal and ileal mucosal DNA and protein, and jejunal and ileal crypt depth compared with SBS animals. SBS-INS rats also had a greater cell proliferation index in both jejunum and ileum and a trend toward a decrease in enterocyte apoptotic index in jejunum and ileum compared with the SBS untreated
\end{abstract}

Igor Sukhotnik and Jorge Mogilner contributed equally to the preparation of this manuscript.

I. Sukhotnik $(\bowtie) \cdot$ J. Mogilner $\cdot$ J. Bejar

Department of Pediatric Surgery B,

Rappaport Faculty of Medicine, Technion,

Bnai Zion Medical Center, 47 Golomb Street,

P.O.B. 4940, Haifa, 31048, Israel

E-mail: igor-dr@internet-zahav.net

Tel.: + 972-4-8256815/+972-4-8359647

Fax: +972-4-8359620

R. Shamir $\cdot$ N. Shehadeh $\cdot$ M. Hirsh

Rambam Medical Center, Haifa, Israel

A. G. Coran

Section of Pediatric Surgery,

Mott Children's Hospital, University of Michigan,

Ann Arbor, MI, USA group. In conclusion, parenteral insulin stimulates structural intestinal adaptation in a rat model of SBS. Increased cell proliferation is the main mechanism responsible for increased cell mass.

Keywords Short bowel syndrome - Intestinal adaptation $\cdot$ Insulin

\section{Introduction}

Short bowel syndrome (SBS) is defined as an intestinal failure following a loss of intestinal length below the minimal amount necessary for the absorption of nutrients and a normal nutritional status. SBS is a common problem in pediatric surgery and occurs in newborns and infants suffering from necrotizing enterocolitis, intestinal atresia, and volvulus requiring massive intestinal resection [1]. Despite the availability of total parenteral nutrition (TPN), advances in resuscitation, availability of potent antibiotics, and modern techniques of organ support, SBS remains a significant cause of infant morbidity and mortality [2].

Although intestinal transplantation has emerged as a feasible alternative in the treatment of children with SBS in the last two decades, intestinal adaptation remains the only chance for survival in a subset of these patients. Throughout the process of adaptation, the small intestine increases its absorptive performance and its functional capacity in an attempt to meet the body's metabolic and growth needs [3]. Over the past decades, considerable research has focused on identifying those trophic factors that may augment and accelerate bowel regrowth in patients with SBS. These include nutrients and other luminal constituents, gastrointestinal secretions, hormones, and peptide growth factors [4].

The insulin-like growth factor (IGF) family includes three peptides: insulin, insulin-like growth factor I (IGFI), and insulin-like growth factor II (IGF-II) [5]. The recent evidence suggests that both IGF-I and IGF-II are 
involved in modulation of growth and differentiation of normal small bowel [6]. Olanrewaju and coworkers [7] have shown that infusion of IGF-I into the rodent ileum resulted in a twofold increase in mucosal weight and other parameters of bowel growth. Although a positive role for IGF system in postresection intestinal hyperplasia has been reported by many investigators [8,9], little evidence exists that insulin may affect intestinal growth following bowel resection. Recent experimental and clinical studies suggest a possible role for insulin in normal intestinal physiology. In a recent study, we have demonstrated that oral insulin promotes adaptive growth of small bowel in a rat model of SBS (unpublished data). The effect of systemic (parenteral) administration of the insulin has never been described previously. Systemic administration of exogenous hormone or growth factor may not mimic its local effect within the small bowel because of the complexities of the in vivo system [8]. The present study was undertaken to explore the effects of insulin given subcutaneously on the adaptive changes in the mucosa following massive small bowel resection in a rat.

\section{Materials and methods}

\section{Animals}

All studies were conducted in compliance with the guidelines established by the "Guide for the Care and Use of Laboratory Animals," Rappaport Faculty of Medicine, Technion (Haifa, Israel). Sprague-Dawley rats weighing $250-320 \mathrm{~g}$ were housed in individual cages and were acclimated to laboratory conditions $\left(22^{\circ} \mathrm{C}\right.$ with 12-h light/dark cycle) for 3 days.

Twenty-four Sprague-Dawley rats were randomly assigned to three experimental groups. In group A, sham male animals underwent bowel transection and reanastomosis (sham, $n=8$ ); in group $\mathrm{B}$, rats underwent $75 \%$ bowel resection (SBS, $n=8$ ); and in group $\mathrm{C}$, rats underwent a $75 \%$ small bowel resection and were treated with insulin given subcutaneously at a dose of $1 \mathrm{U} / \mathrm{kg}$, twice daily, from day 3 through day 14 (SBS-INS, $n=8$ ).

\section{Surgical procedure}

After an overnight fast, animals were anesthetized with sodium pentobarbital $(45 \mathrm{mg} / \mathrm{kg})$ administered intraperitoneally. Using sterile technique, the abdomen was opened using a midline incision. For sham animals, the intestine was divided and reanastomosed without resection at a point $15 \mathrm{~cm}$ proximal to the ileocecal valve. For SBS rats, a $75 \%$ resection was performed from $5 \mathrm{~cm}$ distal to the ligament of Treitz to $15 \mathrm{~cm}$ proximal to the ileocecal valve. Anastomoses were performed using interrupted sutures of 6-0 silk. In all animals the abdomen was closed in two layers with a running suture of 3-0 Dexon (Davis and Geck, NY,
USA). Postoperatively, animals were allowed water ad libitum immediately after operation and normal chow at the beginning of the 1st postoperative day.

\section{Parameters of intestinal adaptation}

All animals were sacrificed on the 15th postoperative day. The small intestine from the pylorus to the ileocecal valve was removed and divided into two segments: jejunum proximal to anastomosis and terminal ileum. Each segment was weighed and cut longitudinally. Mucosa was scraped using a glass slide, collected, and weighed. Bowel and mucosal weight was calculated per $\mathrm{cm}$ of bowel length per $100 \mathrm{~g}$ of body weight as described previously [10]. DNA and protein were extracted using TRIzol reagent as described by Chomczynski [11]. The DNA concentrations were recorded spectrophotometrically and calculated per $\mathrm{cm}$ of bowel length. Final protein concentration was measured spectrophotometrically using a commercially available kit (Bio-Rad, Protein Assay) and was calculated per $\mathrm{cm}$ of bowel length.

\section{Histological examination}

Intestinal samples from the proximal jejunum and distal ileum were fixed in $10 \%$ formalin, dehydrated in progressive concentrations of ethanol, cleared in xylene, and embedded in paraffin wax. Deparaffinized 5- $\mu \mathrm{m}$ sections were stained with haematoxylin and eosin. Villus height and crypt depth were measured using a graded eye piece at 10 times magnification by a pathologist blinded to the tissue origin.

\section{Enterocyte proliferation and apoptosis}

Crypt cell proliferation determination was assessed using biotinylated monoclonal anti-BrdU antibody system provided in a kit form (Zymed Laboratories, San Francisco, CA, USA), and TUNEL assay for apoptotic cell detection was performed using the I.S. Cell Death Detection kit (Boehringer Mannheim GmbH, Mannheim, Germany). An index of proliferation was determined as the ratio of crypt cells staining positively for BrdU per 10 crypts. The apoptotic index (AI) was defined as the number of apoptotic TUNEL-positive cells per 10 villi. A qualified pathologist blinded to the source of intestinal tissue performed all measurements.

\section{Statistical analysis}

The data are expressed as the mean \pm SEM. Statistical analysis of parameters of adaptation, enterocyte proliferation, and apoptosis was performed using the nonparametric Kruskal-Wallis ANOVA test, followed by 
the corrected Mann-Whitney test, with $P$ less than 0.05 considered statistically significant.

\section{Results}

Body weight

The sham-operated control rats' body weight remained unchanged during the first 4 days, followed by a gradual increase in weight throughout the next 10-day observation period (Fig. 1). Bowel resection (group B) caused a significant reduction in weight during the first 4 days, followed by a gradual increase in weight during the next 10 days. However, body weight was significantly lower in SBS rats compared with sham animals. Administration of subcutaneous insulin did not significantly change body weight gain compared with SBS untreated animals.

Overall intestinal and mucosal weights

Overall total intestinal weights expressed as $\mathrm{g} / \mathrm{cm}$ of length/100 g body weight significantly increased in jejunum (threefold, $P<0.05$ ) and ileum (twofold, $P<0.05$ ) in SBS rats (group B) compared with sham (group A) animals (Fig. 2). SBS-INS rats showed higher jejunal $(31 \%, P<0.05)$ and ileal $(22 \%, P<0.05)$ intestinal weight compared with SBS untreated animals. Mucosal weights showed similar changes. Resected animals (group B) showed greater mucosal weight per centimeter of bowel in jejunum (threefold, $P<0.05$ ) and ileum (twofold, $P<0.05$ ) compared with sham (group A) rats (Fig. 2). Subcutaneous insulin injections (group C) led to an additional increase in mucosal weights in jejunum $(35 \%, P<0.05)$ and ileum $(33 \%, P<0.05)$ compared with SBS untreated animals (group B).

\section{Mucosal DNA and protein}

Short bowel syndrome rats (group B) had significantly higher mucosal DNA levels in jejunum (threefold,

\section{Body Weight Changes}

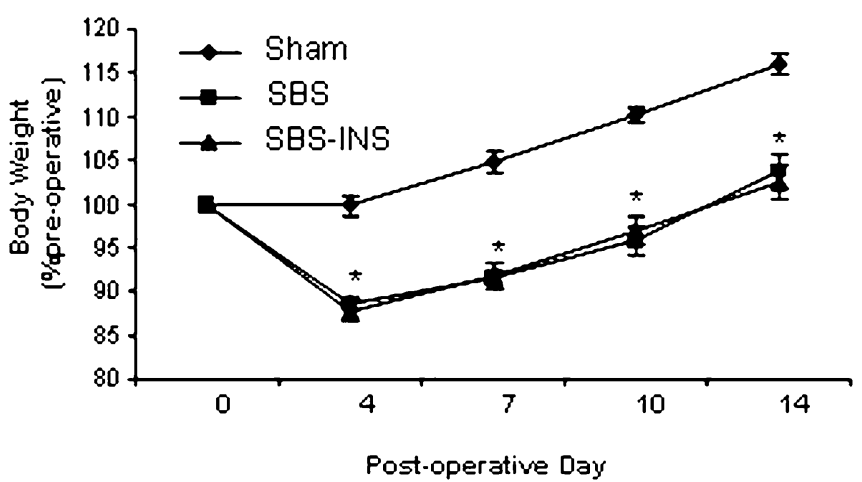

Fig. 1 Body weight changes

\section{Macroscopic Bowel Appearance}

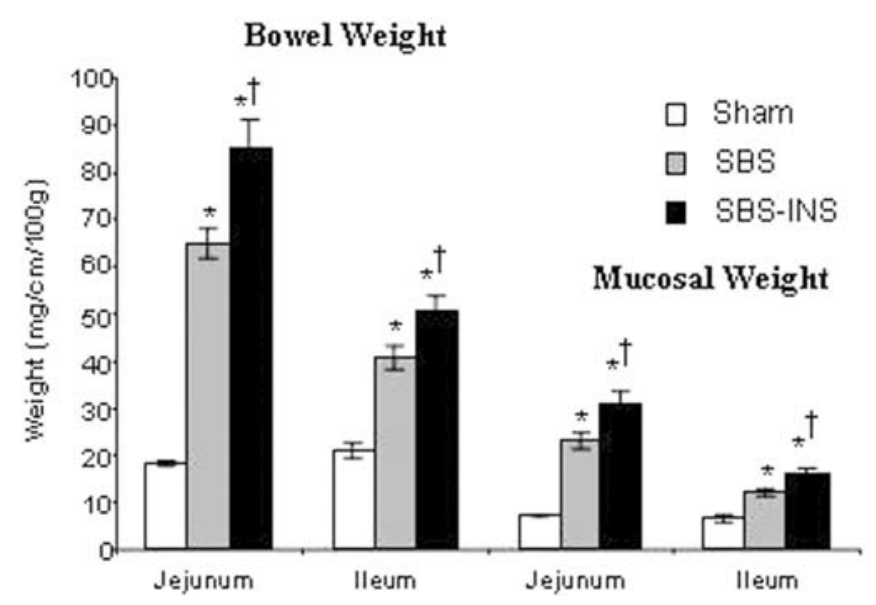

Fig. 2 Macroscopic bowel appearance

$P<0.05)$ and ileum $(33 \%, P<0.05)$ compared with sham (group A) animals (Fig. 3). SBS-INS rats (group C) demonstrated an additional $50 \%$ increase in mucosal DNA in jejunum and ileum compared with SBS untreated animals (group B). SBS rats (group B) demonstrated a threefold increase in mucosal protein in jejunum compared with sham (group A) animals. SBS-INS rats showed a significant increase in mucosal protein in jejunum $(47 \%, P<0.05)$ and ileum $(55 \%$, $P<0.05$ ) compared with SBS untreated (group B) animals.

\section{Histological findings}

The histological changes in remaining bowel are shown in Fig. 4. As expected, bowel resection (group B) resulted in a significant increase in villus height in jejunum $(50 \%, P<0.05)$ and ileum $(49 \%, P<0.05)$, and in crypt depth in jejunum $(29 \%, P<0.05)$ and ileum $(24 \%$,

\section{Mucosal DNA and Protein}

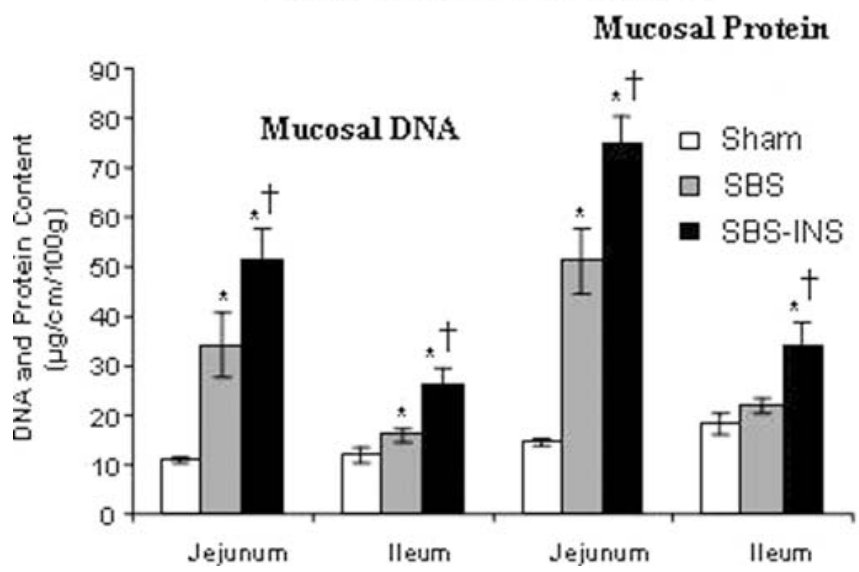

Fig. 3 Mucosal DNA and protein 
Mieroscopic Bowel Appearanee

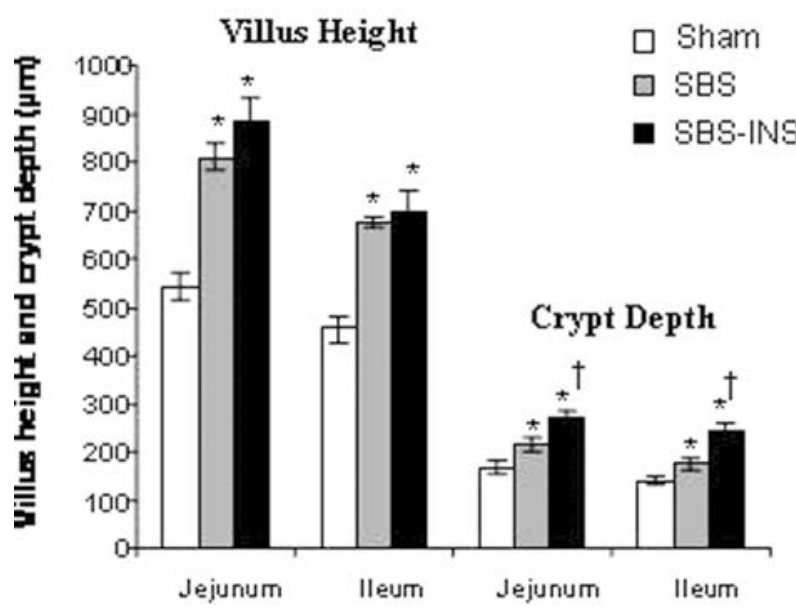

Fig. 4 Microscopic bowel appearance

$P<0.05)$ compared with sham animals (group A). Subcutaneous injections of insulin (group C) led to a significant increase (vs. SBS untreated animals, group B) in crypt depth in jejunum $(25 \%, P<0.05)$ and ileum $(38 \%$, $P<0.05)$ and a trend toward an increase in villus height in jejunum and ileum; however, this trend did not achieve statistical significance.

\section{Cell proliferation and apoptosis}

A significant increase in cell proliferation was seen following bowel resection (group B) compared with sham animals (group A) in jejunum $(270 \pm 15$ vs. $168 \pm 12$ BrdU-positive cells per 10 crypts, $P<0.05$ ) and ileum ( $262 \pm 19$ vs. $190 \pm 7$ BrdU-positive cells per 10 crypts, $P<0.05$ ) (Fig. 5). Following insulin injections, SBS-INS rats (group C) demonstrated an additional increase in the jejunal $(340 \pm 30$ vs. $270 \pm 15$ BrdU-positive cells per 10 crypts, $P<0.05)$ and ileal $(380 \pm 39$ vs.

\section{Enterocyte Proliferation}

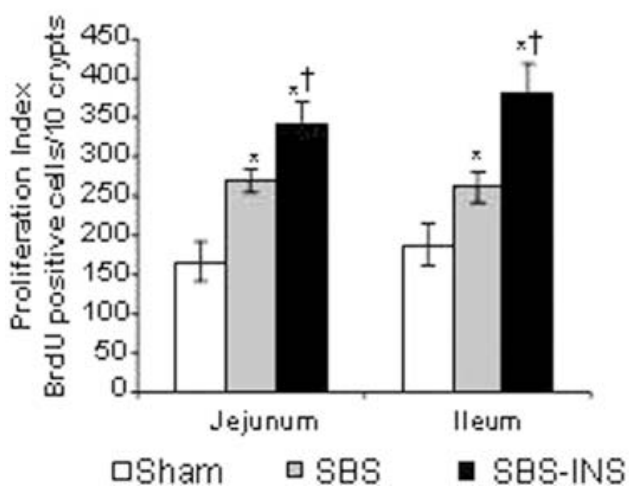

Fig. 5 Enterocyte proliferation
$262 \pm 19$ BrdU-positive cells per 10 crypts, $P<0.05$ ) proliferation rates compared with SBS untreated animals (group B).

Short bowel syndrome rats showed a significant increase in enterocyte apoptosis in jejunum $(21.32 \pm 3.4$ vs. $9.2 \pm 3$.three apoptotic cells per five villi, $P<0.05)$ and ileum $(28.2 \pm 3.4$ vs. $16 \pm 5$ apoptotic cells per five villi, $P<0.05)$ compared with sham animals (Fig. 6). Following subcutaneous insulin, SBS rats showed a tendency toward a decrease in cell apoptosis in jejunum and ileum compared with SBS untreated animals; however, this trend did not achieve statistical significance.

\section{Discussion}

The IGF system was discovered as a group of factors in serum that mediate the growth-promoting effects of growth hormone on skeleton [12]. This system includes the ligands IGF-I and IGF-II, the receptors IGFRs type 1 and type 2, and six high-affinity binding proteins (IGFBPs 1-6) that modulate IGF cellular actions [8]. The role of the IGF system in the growth and differentiation of bowel during development has been reported by many investigators $[13,14]$ A growing body of evidence suggests that IGF-I mediates many of the enterotrophic actions of growth hormone. It is believed that growth hormone stimulates intestinal adaptation in patients with SBS through modulation of IGF-I [9]. In many animal models of SBS, systemic or local IGF-I administration enhanced bowel regrowth and improved nutrient absorption $[9,15]$. Although positive effects of IGF-I in SBS have been reported by many investigators, little evidence exists that insulin may affect intestinal growth following bowel resection. Recent experimental and clinical studies suggest a possible role for insulin in normal intestinal physiology. Insulin stimulates the epithelial cell proliferation and differentiation of intestinal epithelial cells in vitro [16]. Insulin-receptor densities are selectively associated with intestinal mucosa growth in neonatal calves [17]. Insulin has trophic effects on intestinal mucosa in the newborn miniature pig [18], accelerates enterocytes proliferation in the intestinal mucosa of suckling mice [19], and increases fermental activities in villus cells and the concentration of the secretory component of immunoglobulins in crypt cells in rats [20].

Because there is some evidence that insulin has trophic effects on gut, we hypothesized that this agent could enhance intestinal regeneration following massive small bowel resection. Insulin might stimulate mucosal hyperplasia by a direct stimulation of proliferation or cell migration, or by inhibition of enterocyte apoptosis. Alternatively, it might exert its pro-adaptive effect by stimulating the release of various trophic agents or by altering absorption and secretion of different nutrients.

Our results show that bowel resection in a rat results in apparent stimulation of structural intestinal adaptation. This is evident from increased bowel and mucosal 
Fig. 6 Enterocyte apoptosis

\section{Enterocyte Apoptosis}

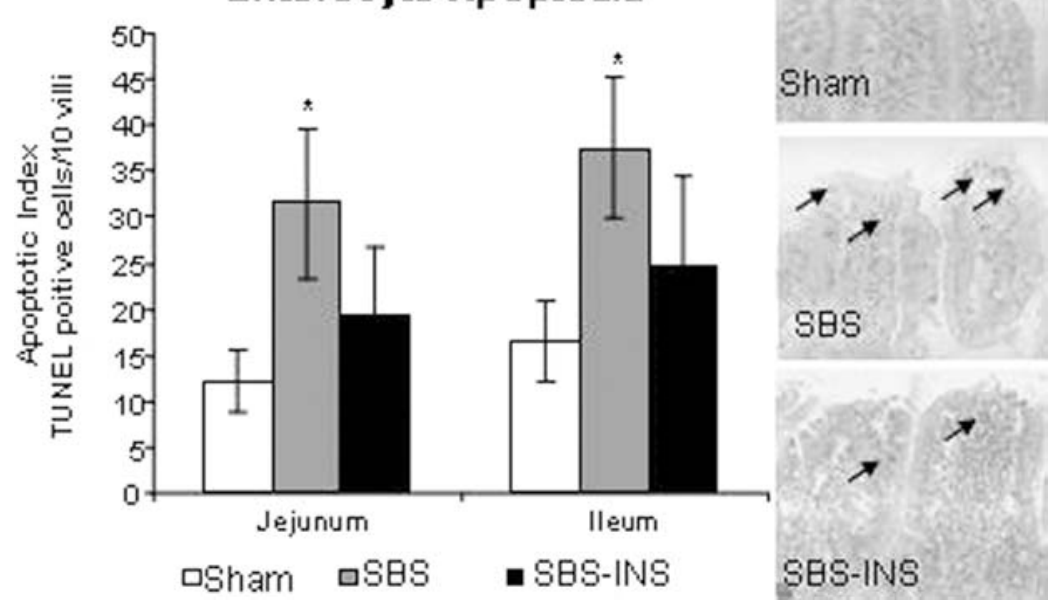

weight, mucosal DNA and protein content, villus height, and crypt depth. Our findings suggest that proliferation of crypt cells increased significantly following bowel resection and was closely correlated with increased crypt depth. An increased cell apoptosis may be considered a mechanism that counterbalances the increased enterocyte proliferation in order to reach a new homeostatic set during intestinal adaptation and promotes disposal of genetically aberrant stem cells and prevents tumorogenesis. Mucosal response to massive resection in our experiment is comparable to the changes previously observed in our laboratory [21, 22].

In our experiment, subcutaneously administered insulin stimulated mucosal hyperplasia, characterized by increased bowel and mucosal weights and increased mucosal DNA and protein. Increases in DNA and protein content in our model suggest that hyperplasia was the predominant adaptive response to insulin administration. Increased crypt depth in both jejunum and ileum suggests increased cell proliferation and was correlated with increased enterocyte proliferation index. Enterocyte death via apoptosis showed a trend toward a decrease; however, this trend did not achieve statistical significance. Increased enterocyte proliferation and a trend toward decreased cell death suggest increased gut epithelial cell turnover following insulin administration and may indicate an adaptive mechanism to increase enterocyte mass. Taken together, these findings suggest that insulin may stimulate gut regrowth following massive small bowel resection in the rat. These preliminary observations suggest that insulin may have clinical utility for the patient with SBS.

\section{References}

1. Booth IW, Lander AD (1998) Short bowel syndrome. Baillieres Clin Gastroenterol 12:739-772
2. Coran AG, Spivak D, Teitelbaum DH (1999) An analysis of the morbidity and mortality of short bowel syndrome in the pediatric age group. Eur J Pediatr Surg 9:228-230

3. O'Brien DP, Nelson LA, Huang FS, et al. (2001) Intestinal adaptation: structure, function, and regulation. Semin Pediatr Surg 10:55-64

4. Thiesen A, Drozdowski L, Iordache C, et al. (2003) Adaptation following intestinal resection: mechanisms and signals. Best Pract Res Clin Gastroenterol 17:981-995

5. Podolsky DK (1994) Peptide growth factors in the gastrointestinal tract. In: Johnson LR (ed) Physiology of the gastrointestinal tract, 3rd edn. Raven Press, New York, pp 129-167

6. Laburthe M, Rouyer-Fessard C, Gammeltoft S (1988) Receptors for insulin-like growth factors I and II in rat gastrointestinal epithelium. Am J Physiol 254:G457-G462

7. Olanrewaju H, Patel L, Seidel ER (1992) Trophic action of local intraileal infusion of insulin-like growth factor I: polyamine dependence. Am J Physiol 263:E282-E286

8. Lund PK (1998) Molecular basis of intestinal adaptation: the role of the insulin-like growth factor system. Ann N Y Acad Sci 859:18-36

9. Ziegler TR, Mantell MP, Chow JC, et al. (1996) Gut adaptation and the insulin-like growth factor system: regulation by glutamine and IGF-1 administration. Am J Physiol 271:G866G875

10. Dowling RH, Booth CC (1967) Structural and functional changes following small intestinal resection in the rats. Clin Sci 32:139-149

11. Chomszynski P (1993) A reagent for the single-step simultaneous isolation of RNA, DNA and proteins from cell and tissue samples. Biotechniques 15:532-536

12. Lund PK (1994) Insulin-like growth factors. In: Dockray G, Walsh JH (eds) Gut peptides: biochemistry and physiology. Raven Press, New York, pp 587-613

13. Lund PK, Moats-Staats BM, Hynes MA, et al. (1986) Somatomedin-C/insulin-like growth factor-I and insulin-like growth factor-II mRNAs in rat fetal and adult tissues. J Biol Chem 261:14539-14544

14. Han VK, Lund PK, Lee DC, et al. (1988) Expression of somatomedin/insulin-like growth factor messenger ribonucleic acids in the human fetus: identification, characterization, and tissue distribution. J Clin Endocrinol Metab 66:422-429

15. Vanderhoof JA, McCusker RH, Clark R, et al. (1992) Truncated and native insulinlike growth factor I enhance mucosal adaptation after jejunoileal resection. Gastroenterology 102:1949-1956 
16. Kojima H, Hidaka H, Matsumura K, et al. (1998) Concerted regulation of early enterocyte differentiation by insulin-like growth factor I, insulin, and transforming growth factor-beta1. Proc Assoc Am Physicians 110:197-206

17. Georgiev IP, Georgieva TM, Pfaffl M, et al. (2003) Insulin-like growth factor and insulin receptors in intestinal mucosa of neonatal calves. J Endocrinol 176:121-132

18. Shulman RJ (1990) Oral insulin increases small intestinal mass and disaccharidase activity in the newborn miniature pig. Pediatr Res 28:171-175

19. Arsenault P, Menard D (1984) Insulin influences the maturation and proliferation of suckling mouse intestinal mucosa in serum free organ culture. Biol Neonate 46:229-236
20. Buts JP, de Kayser N, Dive C (1988) Intestinal development in the suckling rat: effect of insulin on the maturation of villous and crypt functions. Eur J Clin Invest 18:391-398

21. Sukhotnik I, Yakirevich E, Coran AG, et al. (2002) Transforming growth factor-alpha increases enterocyte proliferation, decreases apoptosis and stimulates intestinal adaptation in a rat model of short bowel syndrome. J Surg Res 108:235-242

22. Sukhotnik I, Mor-Vaknin N, Drongowski RA, et al. (2004) Effect of dietary fat on early morphological intestinal adaptation in a rat with short bowel syndrome. Pediatr Surg Int 20(4):235-239 